\title{
Factors predicting successful endoscopic balloon dilatation of esophageal strictures in children - a retrospective study
}

\author{
Dongling Dai \\ Shenzhen Children's Hospital \\ Sixi Liu \\ Shenzhen Children's Hospital \\ Qinghua Yang \\ Shenzhen Children's Hospital \\ Chenxi Zhang \\ Shenzhen Children's Hospital \\ Yigui Zou \\ Shenzhen Children's Hospital \\ Shaoming Zhou \\ Shenzhen Children's Hospital \\ Bingsheng Zheng \\ Shenzhen Children's Hospital \\ Feiqiu Wen ( $\nabla$ fwen62@163.com)
}

Research article

Keywords: Endoscopic balloon dilatation, nonsurgical, pediatric, treatment, risk factor

Posted Date: June 25th, 2019

DOI: https://doi.org/10.21203/rs.2.10642/v1

License: (9) (1) This work is licensed under a Creative Commons Attribution 4.0 International License. Read Full License 


\section{Abstract}

Background \& Aims: Endoscopic balloon dilatation has become the first line treatment for benign esophageal strictures; It is important to know the factors predicting successful outcome to assist in selecting optimal protocol to obtain the best outcome and avoid as many complication as possible. This study aimed to assess the factors predicting outcome of endoscopic balloon dilatation treatment for esophageal stricture in children. Methods: All the patients with benign esophageal stricture treated by endoscopic balloon dilatation from January 2010 to December 2014 were included. All procedures were performed under tracheal intubation and intravenous anesthesia using the 3rd grade controlled radial expansion balloon with the gastroscope. Outcomes were recorded and predictors for outcomes were analyzed. Results: A total of 170 dilations were completed in 64 patients. The success rate was $96.9 \%$. The rates of response, complication, and recurrence were $96.77 \%, 8.06 \%$, and $3.33 \%$, respectively. The number of dilatation sessions and complications were significant higher in patients with smaller diameter strictures $(P=0.013,0.023)$, and in patients with multiple structures $(P=0.014,0.004)$; more complication and recurrences were seen in patients with longer strictures $(P=0.001,0.012)$. The longer the interval between surgery and first dilatation the more sessions and the poorer the response in the patients with anastomotic esophageal strictures $(p=0.017,0.024)$. Conclusions: The diameter, length and number of stricture were the most important risk factors for poor outcomes of endoscopic balloon dilatation treatment of esophageal stricture.

\section{Background}

Benign esophageal stricture (ES) is a problem that pediatric gastroenterologists often encounter. Esophageal strictures in children may develop from esophageal surgery, congenital constriction, or as a result of caustic injury and esophagitits caused by gastroesophageal reflux (1-3). This condition can result in the clinical syndrome of persistent nonbilious vomiting and dysphagia, and the most common clinical consequences are malnutrition and failure to thrive in children.

Benign esophageal strictures in children can be treated surgically or nonsurgically. Over the past 20 years, endoscopic balloon dilation (EBD) therapy has become a primary method. The advantages and safety of EBD was reported with high success and low complication and mortality rates (4-11). However, few studies have focused on the factors such as the etiologies of stricture, the number of the stricture, the length of stricture, the interval between first EBD and surgery/injury/symptom onset, and sessions of EBD which affect the outcome of the treatment. Additionally, the sample size was relatively small and lack of studies on Chinese children was the limitation in the existing literatures. In this retrospective study of 64 Chinese children, we aimed to evaluate the response, safety and more important - the factors predicting outcome of EBD treatment for esophageal strictures.

\section{Methods}

\subsection{Patients}

The current study was a single-site retrospective study. The Ethics Committees of Shenzhen Children's Hospital approved the study protocol. The medical records of 64 pediatric patients under 18 years of age, who were treated with EBD for benign esophageal stricture in Shenzhen Children's Hospital from January 2010 to December 2014, were investigated retrospectively. The patients treated by surgery or the use of adjuvant treatments were excluded.

All the patients were diagnosed with benign ES based on detailed history as obtained from the patient or parents, dysphagia symptoms, upper gastrointestinal radiography and endoscopic appearance. The dysphagia scoring system (12) was applied to the children older than 6 months. The score scaled from 0 to 4 : 0 , no dysphagia; 1 , unable to swallow certain solids; 2 , able to swallow soft foods; 3 , able to swallow only liquids; 4 , unable to swallow even liquids. The infants younger than 6 months were evaluated by clinical presentation and endoscopy. The follow-up period ranged from 36 to 60 months. The demographic features, features of the strictures and outcomes were recorded. The success rate, complications, response, and recurrence rate were comparatively evaluated, and the risk factors were analyzed.

\subsection{Endoscopic technique}

After written consent was obtained from the children's parents, endoscopy and dilatation were performed under general anesthesia with endotracheal intubation. Firstly, the controlled radial expansion wire-guided balloon dilator (Boston Scientific, Cork, Ireland) was introduced and positioned across the stricture under the direct guidance of the endoscope (GIF-Q260J; Olympus, Tokyo, Japan), then the balloon was inflated with saline to achieve the desired pressure and maintained for 3 minutes, after that the pressure of the balloon was released for 3 minutes. Each dilatation session consisted of 2 to 3 threeminute multistep inflations of the balloon with incremental diameter until adequate dilatation was achieved. The length of the balloon is $5.5 \mathrm{~cm}$, and the diameters range from 6 to $18 \mathrm{~mm}$ (Boston Scientific, Cork, Ireland. REF: M0058390, M0058400, M0058410, M0058420). The size of the balloon was chosen depending on the diameter of the esophageal stricture portion which was assessed under endoscopy - the diameter of the endoscope is 9 mm. The first dilation was usually performed with a balloon about 2-3 $\mathrm{mm}$ larger than the stricture. All the patients were followed up as outpatients after successful dilatation. The dilatation frequency was once every $3-4$ weeks if symptoms of obstruction were present, after that the frequency was individualized to once every 4 - 12 weeks according to stricture appearance at endoscopy or patient complaints.

The treatment effectiveness was judged based on improvement of symptoms. It was considered as effective response if a patient had disappearance or relief of dysphagia or dysphagia score of 1 for children older than 6 months for at least 1 year after last dilatation. We defined failure as resistance to EBD (no alteration of stricture diameter when dilated). The return of dysphagia more than 1 year after the last EBD was considered as recurrence.

\subsection{Statistical Analysis}

Statistical presentation and analysis was conducted using Statistical package SPSS 19.0 (SPSS Inc., Chicago, USA). Continuous variables are expressed as the mean \pm SD. The Student's t-test was used for the comparison between groups; if the number of groups was 2 or more, the analysis of variance (ANOVA) 
was applied. Categorical variables were analyzed using the chi-square test. Spearman rank order correlations analysis, for nonparametric correlation, was applied to test correlations between variables. Two-tailed p-values less than 0.05 were considered statistically significant.

\section{Results}

\subsection{Demographic characteristics of patients}

64 children were diagnosed with ES in this study (age range 1 -150 months, median age 22.1 months; female/male ratio, 30/34). The main etiologies of esophageal stricture were post-surgical stenosis after esophageal atresia repair, caustic injury, congenital stricture, and post-reflux esophagitis. The demographic and clinical characteristics of patients are given in Table 1.

\subsection{Strictures}

As shown in table 1, most cases had a single stricture site. The most frequently involvement was the lower third of the esophagus. The stricture was significantly greater after dilatation than it was before treatment (Table 2).

\subsection{Outcomes of treatment}

A total of 170 dilations were done for the 64 patients, ranging from 1 to 6 sessions per patient. 2 cases failed and underwent surgery. $96.77 \%$ of the patients with successful management had symptom improvement. All the children with effective treatment were fed with solid or semi-liquid diet. Improvement in nutrition and failure to thrive was achieved. The relapse of symptoms occurred in 2 patients who received treatment with renewed EBD and are still being followed up. None of the patients died during the follow-up period after EBD. Outcomes of EBD procedure are presented in Table 2.

The most common complications in this study included esophageal perforation, bleeding, infection, and gastroesophageal reflux. Multiple complications occurred in 2 patients. One suffered perforation, aspiration, reflux esophagitis and infection, and the other one suffered perforation and infection. All the patients with complications recovered with conservative treatment as follows: pharyngeal suction, parenteral nutrition, systematic intravenous antibiotherapy and anti-reflux medications. The patients who suffered gastroesophageal reflux were treated with omeprazole for decrease production of $\mathrm{HCl}$ for 2 weeks to 2 months.

\subsection{Factors predicting the outcomes of EBD}

The predictive factors are summarized in Table 3, 4 and 5 . There was no significant difference in response, complications and recurrence between the four etiology groups $(p>0.05)$. More complications and sessions were seen in the patients with more than one stricture site $(p=0.004,0.014)$ and in patients with smaller diameter strictures $(p=0.023,0.013)$. The length of the stricture was significantly associated with complications and recurrence $(p=0.001$ and 0.012). Moreover, a longer interval between surgery and the first EBD was related to more EBD sessions and poorer response in the patients with anastomotic esophageal strictures $(p=0.017,0.024)$.

\section{Discussion}

In this study, we found that stricture length was an import risk factor of EBD treatment for ES in children, which has a significant impact on the complications of EBD. 2 (14.3\%) children with $2-5 \mathrm{~cm}$ stricture and $3(37.5 \%)$ children with stricture longer than $5 \mathrm{~cm}$ suffered complication. The results were similar to the previous observations in which the complication rates were very high in cases that had strictures longer than $5 \mathrm{~cm}$ (4). Previous studies also state that treatment results are better in patients with shorter stricture lengths $(13,14)$. The short stricture treatment was also of significantly shorter duration than the long stricture treatment (15). However, we did not find the association of the length of stricture with success rate and EBD sessions. This is in contrast to the studies which reported that patients with long strictures $(>5 \mathrm{~cm})$ required a significantly higher number of sessions than those with shorter strictures $(1,5)$. We considered that lumen tortuosity, deformation and diverticulization due to long stricture, which contributed to the adverse impact on endoscopic procedures and resulted in more complications.

The diameter and number of strictures was also an important predicting factor in this study, which significantly affected the complication rate and number of EBD sessions needed for all patients, but this did not affected the rate of success, response and recurrence. The present results were in agreement with other observations in which more complications and more sessions were seen in the patients with multiple strictures $(5,16)$. Though in cases with small and/or multiple stricture, EBD was performed in combination with fluoroscopy to avoid the complication as possible, for advancing a balloon without guidewire leads to fibrotic or ulcer, leads to direct perforation as a result of hooking of the tip to the stricture (6), and for a wrong passage that the esophageal diverticulum was mistaken for a stricture to be dilated, which leads to perforation after the balloon is blown in cases of multiple stricture. Moreover, It was likely that substantially higher shear force was necessary to achieve the same expected diameter using a small size of balloon than a larger one, for example, 10 atm force was needed to get the same diameter of $8 \mathrm{~mm}$ with the use of 6-7-8 $\mathrm{mm}$ balloon while just 3 atm force by using 8-9-10 mm balloon. More shearing force was exerted on the esophagus in patients with smaller stricture diameter. Whether some alternative methods are better than endoscopic balloon dilatation remains an issue in management of pediatric patients with multiple esophageal strictures and needs to be investigated further.

Number of EBD sessions was not a predictive factor of clinical outcomes in this study. When we compared the failure and complication rates of the first two EBD procedures with those of subsequent dilatations in patients requiring more than two procedures we did not find any higher risk of failure or complication in the subsequent procedures. It was reported that the recurrence and complications were more frequent in patients who underwent a higher number of dilatations and steroid injection (4), use of multiple dilations led to increased perforation risk (17). 
Etiology of esophageal strictures was reported to be a crucialy important factor determining the outcome of EBD. But we did not find that etiology affected the clinical outcomes in this study. There are some reports revealing that the results are less satisfactory in cases of corrosive injury than with other etiologies for more dilatation sessions $(1,16,18)$, lower effectiveness rates (4), and higher complication and failure rates (19-21), possibly because of the rapid restenosis due to formation of fibrous tissue after dilatation $(13,22-24)$. On the contrary, we found that the EBD sessions, complication and success rate were not significant higher in patients with caustic esophageal strictures than those with other etiologies in this study. However, a lower success rate was in patients with congenial esophageal stricture compared with the other patients, but it was not significant. The results of this study indicated that EBD should be the first line of treatment in cases of corrosive injury, as well as of other etiologies.

Specifically, the time of first EBD after surgery finding in this study was a major predictor of treatment outcome in the patients with anastomotic esophageal strictures. The interval between surgery and the first EBD was significant associated with the number of EBD sessions. Early EBD was related to fewer EBD sessions. This finding is similar to the previous reports of different series in which time to diagnosis or onset of stricture is the most important factor affecting recurrence after dilation $(25,26)$. The observations on adult patients with gastrectomy for gastric cancer indicated balloon dilations earlier than 90 days after surgery require careful observation for restenosis (27). Early EBD has a positive impact on treatment success in patients with caustic esophageal strictures (28). However, the optimal time of initial dilation remains to be determined, because there is always concern that performing dilation 2-3 weeks after surgery might be too early in the healing process and would put the anastomosis at risk for perforation (29). We suggest the time of initial EBD not exceeding 2 months after surgery.

The shortcomings to our study include the relatively short follow-up period and a small sample size resulting in small subgroup size.

\section{Conclusions}

This study indicated that the length, diameter and number of the strictures were the most crucial predictive factors for treatment outcome. Early EBD after surgery was related to better response and fewer EBD sessions in the patients with anastomotic esophageal stricture.

\section{Abbreviations}

AS, anastomotic stricture; EBD, endoscopic balloon dilatation; $\mathrm{ES}$, esophageal stricture; $\mathrm{Cl}$, caustic injury; CS, congenital stricture.

\section{Declarations}

Ethical approval: The Ethics Committees of Shenzhen Children's Hospital approved this current study.

Informed consent statement: The informed consent was waived due to the retrospective nature of this study.

Consent for publication: Not applicable

Availability of data and material: All data analyzed during the current study are included in this published article.

Competing interests: All authors declare no (financial) conflict of interest.

Funding: This study was funded by Shenzhen Innovation and Technology Committee (Grant number JCYJ20180228175150018) and Guangdong medical research fund project (Grant number A2018550).

\section{Acknowledgments}

The authors wish to thank the patients and their families for allowing us to use the medical documentation and information leading to the present article.

\section{Authors' contributions}

FW conceived and designed the study. SL supervised the study and interpreted the data. DD treated patients by endoscopic balloon dilatation and prepared the manuscript. QY, BZ took care of patients, collected and analyzed the data. All authors have read and approved the final version for publication.

\section{References}

1. Broor SL, Lahoti D, Bose PP, Ramesh GN, Raju GS, Kumar A. Benign esophageal strictures in children and adolescents: etiology, clinical profile, and results of endoscopic dilation. Gastrointestinal endoscopy. 1996;43(5):474-7.

2. Shah MD, Berman WF. Endoscopic balloon dilation of esophageal strictures in children. Gastrointestinal endoscopy. 1993;39(2):153-6.

3. Allmendinger N, Hallisey MJ, Markowitz SK, Hight D, Weiss R, McGowan G. Balloon dilation of esophageal strictures in children. Journal of pediatric surgery. 1996;31(3):334-6.

4. Cakmak M, Boybeyi O, Gollu G, Kucuk G, Bingol-Kologlu M, Yagmurlu A, et al. Endoscopic balloon dilatation of benign esophageal strictures in childhood: a 15-year experience. Diseases of the esophagus : official journal of the International Society for Diseases of the Esophagus. 2016;29(2):179-84.

5. Chang CF, Kuo SP, Lin HC, Chuang CC, Tsai TK, Wu SF, et al. Endoscopic balloon dilatation for esophageal strictures in children younger than 6 years: experience in a medical center. Pediatrics and neonatology. 2011;52(4):196-202. 
6. Akarsu C, Unsal MG, Dural AC, Kones O, Kocatas A, Karabulut M, et al. Endoscopic balloon dilatation as an effective treatment for lower and upper benign gastrointestinal system anastomotic stenosis. Surgical laparoscopy, endoscopy \& percutaneous techniques. 2015;25(2):138-42.

7. Santos P, Simoes C, Lopes J, Carrilho Ribeiro L, Velosa J. Endoscopic balloon dilation of oesophageal stenosis in a patient with recessive dystrophic epidermolysis bullosa. Gastroenterologia y hepatologia. 2018.

8. Osuga T, Ikura Y, Hasegawa K, Hirano S. Use of endoscopic balloon dilation for benign esophageal stenosis in children: our 11 year experience. Esophagus. 2017;15(1):47-51.

9. Taskinlar H, Bahadir GB, Yigit D, Erdogan C, Avlan D, Nayci A. Effectiveness of endoscopic balloon dilatation in grade $2 a$ and $2 b$ esophageal burns in children. Minimally invasive therapy \& allied technologies : MITAT : official journal of the Society for Minimally Invasive Therapy. 2017;26(5):300-6.

10. Lang M, Brietzke SE. A systematic review and meta-analysis of endoscopic balloon dilation of pediatric subglottic stenosis. Otolaryngology-head and neck surgery : official journal of American Academy of Otolaryngology-Head and Neck Surgery. 2014;150(2):174-9.

11. Hsieh KH, Soong WJ, Jeng MJ, Lee YS, Tsao PC, Chou YL. Flexible endoscopic diagnosis and treatment of esophageal stenosis in children with noninvasive ventilation support. Pediatrics and neonatology. 2018;59(1):31-4.

12. Antoniou D, Soutis M, Christopoulos-Geroulanos G. Anastomotic strictures following esophageal atresia repair: a 20-year experience with endoscopic balloon dilatation. Journal of pediatric gastroenterology and nutrition. 2010;51(4):464-7.

13. Temiz A, Oguzkurt P, Ezer SS, Ince E, Hicsonmez A. Long-term management of corrosive esophageal stricture with balloon dilation in children. Surgical endoscopy. 2010;24(9):2287-92.

14. Gundogdu HZ, Tanyel FC, Buyukpamukcu N, Hicsonmez A. Conservative treatment of caustic esophageal strictures in children. Journal of pediatric surgery. 1992;27(6):767-70.

15. Uygun I, Arslan MS, Aydogdu B, Okur MH, Otcu S. Fluoroscopic balloon dilatation for caustic esophageal stricture in children: an 8-year experience. Journal of pediatric surgery. 2013;48(11):2230-4.

16. Shehata SM, Enaba ME. Endoscopic dilatation for benign oesophageal strictures in infants and toddlers: experience of an expectant protocol from North African tertiary centre. African journal of paediatric surgery : AJPS. 2012;9(3):187-92.

17. Katzka DA, Castell DO. Review article: an analysis of the efficacy, perforation rates and methods used in pneumatic dilation for achalasia. Alimentary pharmacology \& therapeutics. 2011;34(8):832-9.

18. Bittencourt PF, Carvalho SD, Ferreira AR, Melo SF, Andrade DO, Figueiredo Filho PP, et al. Endoscopic dilatation of esophageal strictures in children and adolescents. Jornal de pediatria. 2006;82(2):127-31.

19. Yeming W, Somme S, Chenren S, Huiming J, Ming Z, Liu DC. Balloon catheter dilatation in children with congenital and acquired esophageal anomalies. Journal of pediatric surgery. 2002;37(3):398-402.

20. Kang SG, Song HY, Lim MK, Yoon HK, Goo DE, Sung KB. Esophageal rupture during balloon dilation of strictures of benign or malignant causes: prevalence and clinical importance. Radiology. 1998;209(3):741-6.

21. Song HY, Han YM, Kim HN, Kim CS, Choi KC. Corrosive esophageal stricture: safety and effectiveness of balloon dilation. Radiology. 1992;184(2):373-8.

22. Alshammari J, Quesnel S, Pierrot S, Couloigner V. Endoscopic balloon dilatation of esophageal strictures in children. International journal of pediatric otorhinolaryngology. 2011;75(11):1376-9.

23. Bicakci U, Tander B, Deveci G, Rizalar R, Ariturk E, Bernay F. Minimally invasive management of children with caustic ingestion: less pain for patients. Pediatric surgery international. 2010;26(3):251-5.

24. Doo EY, Shin JH, Kim JH, Song HY. Oesophageal strictures caused by the ingestion of corrosive agents: effectiveness of balloon dilatation in children. Clinical radiology. 2009;64(3):265-71.

25. Park JH, Kim KY, Song HY, Cho YC, Kim PH, Tsauo J, et al. Radiation-induced esophageal strictures treated with fluoroscopic balloon dilation: clinical outcomes and factors influencing recurrence in 62 patients. Acta radiologica. 2018;59(3):313-21.

26. Tuna Y, Kocak E, Dincer D, Koklu S. Factors affecting the success of endoscopic bougia dilatation of radiation-induced esophageal stricture. Digestive diseases and sciences. 2012;57(2):424-8.

27. Lee HJ, Park W, Lee H, Lee KH, Park JC, Shin SK, et al. Endoscopy-guided balloon dilation of benign anastomotic strictures after radical gastrectomy for gastric cancer. Gut and liver. 2014;8(4):394-9.

28. Uygun I, Aydogdu B, Okur MH, Arayici Y, Celik Y, Ozturk H, et al. Clinico-epidemiological study of caustic substance ingestion accidents in children in Anatolia: the DROOL score as a new prognostic tool. Acta chirurgica Belgica. 2012;112(5):346-54.

29. Kim IO, Yeon KM, Kim WS, Park KW, Kim JH, Han MC. Perforation complicating balloon dilation of esophageal strictures in infants and children. Radiology. 1993;189(3):741-4.

\section{Tables}

Table 1. Characteristics of the patients and the strictures in this study 


\begin{tabular}{lcc}
\hline & Characteristics & Patients (N=64) \\
\hline sex & male & $34(53.1 \%)$ \\
Length of stricture & female & $30(46.9 \%)$ \\
& $\leq 2 \mathrm{~cm}$ & $14(21.9 \%)$ \\
Stricture sites & $2-5 \mathrm{~cm}$ & $42(65.6 \%)$ \\
& $\geqq 5 \mathrm{~cm}$ & $8(12.5 \%)$ \\
Etiologies & single & $58(90.6 \%)$ \\
& multiple & $6(9.4 \%)$ \\
& AS & $36(56.3 \%)$ \\
& CI & $16(25.0 \%)$ \\
Location of stricture & CS & $8(12.5 \%)$ \\
& PRE & $4(6.25 \%)$ \\
& upper third esophageal & $10(15.6 \%)$ \\
& middle third esophageal & $24(37.5 \%)$ \\
†AS, anastomotic stricture; CI, caustic injury; CS, congenital stricture; PRE, post-reflux esophagitis
\end{tabular}

Table 2. Outcomes of endoscopic balloon dilatation in this study

\begin{tabular}{llc}
\hline \multicolumn{2}{c}{ Outcomes } & Results (N=64) \\
\hline Age at first EBD (months) & $22.43 \pm 3.01$ \\
Interval $^{\dagger}$ (months) & & $10.45 \pm 1.69$ \\
Sessions & & $2.19 \pm 0.24$ \\
Follow-up (months) & & $42.88 \pm 14.30$ \\
Diameter (mm) & before first EBD & $5.13 \pm 0.37$ \\
& after final EBD & $10.05 \pm 0.34$ \\
Success & P value & 0.014 \\
& Success & $62(96.9 \%)$ \\
Complications & Failure & $2(3.1 \%)$ \\
& perforation & $4(6.45 \%)$ \\
& bleeding & $2(3.23 \%)$ \\
& reflux esophagitis & $1(1.61 \%)$ \\
& infection & $1(1.61 \%)$ \\
& multiple & $2(3.23 \%)$ \\
Response & total & $5(8.06 \%)$ \\
& no complication & $57(91.9 \%)$ \\
& Effective remission & $54(87.10 \%)$ \\
& & $6(9.68 \%)$ \\
Recurrence & non-effective & $60(96.77 \%)$ \\
& non-relapse & $2(3.23 \%)$ \\
& relapse & $58(96.67 \%)$ \\
\hline
\end{tabular}

Interval $^{\dagger}$ : Interval between first EBD and surgery/injury/symptom onset.

${ }^{*} \mathrm{P}<0.05$

Table 3. The correlations between outcomes of EBD and risk factors

\begin{tabular}{lccccc}
\hline Outcomes & \multicolumn{2}{c}{ Interval $^{\dagger}$ (months) } & & \multicolumn{2}{c}{ Diameter before EBD $(\mathrm{cm})$} \\
\cline { 2 - 3 } \cline { 5 - 6 } & $\mathrm{r}_{\mathrm{s}}$ & $\mathrm{P}$ value & & $\mathrm{r}_{\mathrm{s}}$ & P value \\
\hline Complications & 0.011 & 0.645 & & -0.406 & $0.023^{*}$ \\
Response & -0.174 & 0.348 & & 0.219 & 0.237 \\
Recurrence & 0.162 & 0.383 & & -0.150 & 0.421 \\
Sessions & 0.015 & 0.934 & & -0.271 & $0.013^{*}$ \\
\hline
\end{tabular}

$\mathrm{r}_{\mathrm{s}}$ : rank correlation coefficient.

${ }^{*} \mathrm{P}<0.05$

Table 4. Factors predicting the outcomes of EBD treatment in this study

\begin{tabular}{|c|c|c|c|c|c|c|c|c|c|c|c|c|c|c|}
\hline \multirow[t]{2}{*}{ Jutcomes } & \multicolumn{5}{|c|}{ Etiologies } & \multicolumn{5}{|c|}{ Length } & \multicolumn{4}{|c|}{ Number of strictures } \\
\hline & $\begin{array}{c}\text { AS } \\
n=36\end{array}$ & $\begin{array}{c}\text { CI } \\
n=16\end{array}$ & $\begin{array}{l}\text { CS } \\
n=8\end{array}$ & $\begin{array}{l}\text { PRE } \\
n=4\end{array}$ & $\begin{array}{c}\text { statistic } \mathrm{P} \\
\text { value value }\end{array}$ & $\begin{array}{l}\leq 2 \mathrm{~cm} \\
\mathrm{n}=42\end{array}$ & $\begin{array}{c}2-5 \mathrm{~cm} \\
\mathrm{n}=14\end{array}$ & $\begin{array}{l}\geqq 5 \mathrm{~cm} \\
\mathrm{n}=8\end{array}$ & $\begin{array}{l}\text { statistic } \\
\text { value }\end{array}$ & $\begin{array}{c}\mathrm{P} \\
\text { value }\end{array}$ & $\begin{array}{l}\text { Single } \\
n=58\end{array}$ & $\begin{array}{c}\text { Multiple } \\
n=6\end{array}$ & $\begin{array}{l}\text { statistic } \\
\text { value }\end{array}$ & $\begin{array}{c}\mathrm{P} \\
\text { value }\end{array}$ \\
\hline $\begin{array}{l}\text { Response } \\
\text { (score) }\end{array}$ & $-2.20 \pm 0.45$ & $-2.18 \pm 0.50$ & $-2.16 \pm 0.39$ & $-2.19 \pm 0.45$ & $F=2.2700 .758$ & $-2.21 \pm 0.51$ & $-2.17 \pm 0.39$ & $-2.17 \pm 0.43$ & $\mathrm{~F}=1.431$ & 0.313 & $-2.18 \pm 0.41$ & $-2.15 \pm 0.65$ & $\mathrm{~F}=2.178$ & 0.180 \\
\hline (n) & 1 & 1 & 0 & 0 & $c^{2}=1.1790 .758$ & 0 & 0 & 2 & $c^{2}=8.802$ & $0.012^{*}$ & 1 & 1 & $\mathrm{OR}=9.667$ & 0.180 \\
\hline $\begin{array}{l}\text { Sessions } \\
\mathrm{x} \pm \mathrm{SD})\end{array}$ & $2.61 \pm 0.36$ & $2.00 \pm 0.38$ & $1.82 \pm 0.20$ & $1.80 \pm 0.22$ & $\mathrm{~F}=1.8630 .159$ & $1.95 \pm 0.28$ & $2.57 \pm 0.43$ & $2.75 \pm 0.62$ & $\mathrm{~F}=1.729$ & 0.416 & $2.04 \pm 0.22$ & $4.12 \pm 0.67$ & $\mathrm{~F}=6.797$ & $0.014^{*}$ \\
\hline
\end{tabular}


Table 5. Correlations between risk factors and outcomes in patients with anastomotic esophageal strictures.

\begin{tabular}{|c|c|c|c|c|c|c|c|c|}
\hline \multirow[t]{2}{*}{ Outcomes } & \multicolumn{2}{|c|}{ Interval $^{\dagger}$ (months) } & \multicolumn{2}{|c|}{ Sessions } & \multicolumn{2}{|c|}{$\begin{array}{c}\text { Length } \\
(\mathrm{cm})\end{array}$} & \multicolumn{2}{|c|}{ Diameter before EBD $(\mathrm{cm})$} \\
\hline & coefficie & $\mathrm{P}$ value & coefficie & $\overline{P \text { value }}$ & coefficie & $\overline{\mathrm{P} \text { value }}$ & coefficient & $\mathrm{P}$ value \\
\hline Complications & 0.324 & 0.587 & 0.006 & 0.858 & 0.616 & $0.031^{*}$ & 0.724 & $0.012^{*}$ \\
\hline Response & -0.527 & $0.024^{*}$ & -0.019 & 0.672 & -0.324 & 0.437 & -0.319 & 0.346 \\
\hline Recurrence & 0.162 & 0.453 & 0.135 & 0.446 & 0.255 & 0.615 & 0.151 & 0.627 \\
\hline Sessions & 0.338 & $0.017^{*}$ & - & - & -0.312 & 0.411 & 0.612 & $0.031^{*}$ \\
\hline
\end{tabular}

Interval $^{\dagger}$ : Interval between first EBD and surgery/injury/symptom onset.

${ }^{*} \mathrm{P}<0.05$ 